\title{
Anabases
}

ANABASES Traditions et réceptions de l'Antiquité

$24 \mid 2016$

Varia

\section{Sandrine Dubel, Anne-Marie Favreau-Linder et Estelle Oudot (éd.), À l'école d'Homère. La culture des orateurs et des sophistes}

\section{Alain Ballabriga}

\section{(2) OpenEdition}

\section{Journals}

Édition électronique

URL : http://journals.openedition.org/anabases/5752

ISSN : 2256-9421

Éditeur

E.R.A.S.M.E.

\section{Édition imprimée}

Date de publication : 10 novembre 2016

Pagination : 343-344

ISSN : $1774-4296$

Référence électronique

Alain Ballabriga, « Sandrine Dubel, Anne-Marie Favreau-Linder et Estelle Oudot (éd.), À l'école d'Homère. La culture des orateurs et des sophistes ", Anabases [En ligne], 24 | 2016, mis en ligne le 15 novembre 2016, consulté le 22 septembre 2020. URL : http://journals.openedition.org/anabases/5752

Ce document a été généré automatiquement le 22 septembre 2020.

(c) Anabases 


\title{
Sandrine Dubel, Anne-Marie Favreau-Linder et Estelle Oudot (éd.), À l'école d'Homère. La culture des orateurs et des sophistes
}

\author{
Alain Ballabriga
}

\section{RÉFÉRENCE}

Sandrine Dubel, Anne-Marie Favreau-Linder et Estelle Oudot (éd.), À l'école d'Homère. La culture des orateurs et des sophistes, Paris, Éditions Rue d'Ulm, 2015, 295 p.

19 euros/ isbn 978-2-7288-0526-6

1 Cet ouvrage réunit dix-huit articles répartis dans quatre sections. Les trois premières (Grecs et Romains à l'école d'Homère/Stratégies rhétoriques: modèles et détournements/Enjeux critiques) sont des sections thématiques dans lesquelles les articles sont classés dans l'ordre chronologique depuis l'époque classique jusqu'à l'époque romaine (Deuxième Sophistique du Haut Empire) et l'Antiquité tardive avec Libanios (IV ${ }^{\mathrm{e}} \mathrm{s}$. ap.). La quatrième section (Héritages) nous mène de l'école de Gaza ( $\mathrm{V}^{\mathrm{e}}$ $\mathrm{VI}^{\mathrm{e}} \mathrm{s}$.) jusqu'à l'époque des Comnènes (XII ${ }^{\mathrm{e}} \mathrm{s}$.).

Plutôt que de simplement présenter dans l'ordre de l'ouvrage toutes les contributions, dont certaines sont d'un moindre intérêt, il m'a paru plus judicieux d'insister sur quelques temps forts et thèmes récurrents.

Dès l'époque classique on note une grande variété dans la réception d'Homère. Chez des auteurs comme Gorgias, Antisthène, Alcidamas, on peut lire des discours sophistiques mis dans la bouche de héros épiques, en particulier Ulysse, sophiste avant la lettre (p. 33-45). Différemment Isocrate renouvelle la prose en la rendant plus poétique et essaie d'imposer un discours politique opposé à celui des poètes, des sophistes, des philosophes (p. 115-131). Quant à Xénophon, son Socrate, à la différence de Platon, ne 
critique pas l'influence dangereuse d'Homère. C'est sur le mode léger de la plaisanterie, en complément d'une réflexion plus profonde, que Socrate fait appel à la parole homérique (p 175-189).

4 Une égale variété se marque à l'époque impériale. Dans un discours (Sur une remarque faite en passant/Peri tou paraphthegmatos), Aelius Aristide, pour répondre à des critiques visant un éloge de lui-même (periautologia), donne un long répertoire d'éloges de soi où Homère se taille la part du lion, avec en particulier la figure du vieux sage Nestor ( $\mathrm{p}$. 151-162). C'est aussi un cas spécial qu'offre Dion Chrysostome dans son Discours aux Alexandrins où un centon homérique et bouffon de trente-six hexamètres permet de faire la satire de la passion pour les courses de chevaux chez les Alexandrins (p. 133-149). Quant à Plutarque, dans une des Questions de table $(9,13)$, à propos d'une interprétation rhétorique du duel entre Paris et Ménélas au chant III de l'Iliade, il met en œuvre les principes d'Hermogène de Tarse (Des états de cause/ Peri staseôn) dans le cadre d'un banquet de savants où il faut faire preuve de vastes connaissances littéraires et philosophiques pour s'imposer dans le milieu très compétitif des sophistes ( $p$. 191-201).

De façon plus générale, l'étude des exercices d'éloquence (progymnasmata) d'époque romaine permet de saisir la présence d'Homère en sa qualité de dénominateur commun au sein de l'éducation (paideia) antique, en tant que ciment de l'hellénisme, de l'identité grecque, tandis que les textes sont un entrelacement d'épisodes, de thèmes que rhéteurs et étudiants pouvaient à loisir reprendre et modifier (p. 73-86).

6 Deux contributions consacrées à la littérature latine - époque classique (p. 47-60) et Antiquité tardive avec Dracontius (p. 229238) - font entendre un son différent et, à mon sens, pertinent aussi, d'une certaine façon, pour la moitié orientale, hellénophone de l'empire. Ces deux articles en effet font soupçonner que la connaissance du grec dans le monde latin n'était pas aussi répandue et solide que peut le faire penser la lecture de Cicéron ou de Quintilien. Or chez Dion Chrysostome, dont on vient de relever une prouesse, on peut aussi lire un curieux texte (Sur l'entraînement au discours/ Peri logou askêseôs) qui laisse le lecteur avec l'impression que l'on pouvait faire bonne figure en société avec pour tout bagage une solide connaissance de Xénophon, le plus facile des classiques. Pour ma part je trouve ce texte prodigieusement significatif car il permet de soupçonner que même pour des hellénophones d'époque romaine la connaissance des classiques était une rude affaire et que seule une étroite élite pouvait se hisser au niveau des virtuoses étudiés dans le présent ouvrage et dont un des plus remarquables fut Libanios d'Antioche au IV siècle.

7 En effet c'est peut-être chez Libanios que la réception d'Homère se présente sous le jour le plus intéressant, car elle s'accompagne d'une mise à distance de l'héritage littéraire pourtant respecté, d'une critique des vieux mythes et idoles, mise au service des valeurs fondamentales de l'hellénisme. Par exemple Thersite, le vilain de l'épopée, représente un modèle de franc-parler contre l'iniquité des puissants (p. 87-102).

8 C'est encore la figure de Thersite qui apparaît dans une épître d'Énée de Gaza (v. 450-v. 534), philosophe néo-platonicien converti au christianisme, dans le cadre d'un concours de beauté entre Thersite et le beau Nirée. On retrouve le lieu commun (topos) rhétorique de l'éloge paradoxal mais la référence littéraire renvoie aussi à un patrimoine collectif de représentations théâtrales, artistiques, partagé par les érudits et le public des théâtres. Ainsi Chorikios, autre membre de l'école de Gaza, dans son Apologie des mimes (68), fait-il allusion à des mimes bouffons à sujet épique. À l'extrême 
fin de l'Antiquité (vie s.), l'école de Gaza, qui peut encore s'adresser à un public où se mêlent chrétiens et derniers païens, témoigne d'une attitude ludique à l'égard de la poésie homérique, très différente de la position d'un Plutarque ou d'un Basile de Césarée (p. 217-228).

9 Le contexte culturel est fort différent six siècles plus tard sous la dynastie des Comnènes (XII ${ }^{e}$ s.). Dans un éloge impérial d'Eustathe de Thessalonique - surtout connu des hellénistes par ses commentaires à l'épopée homérique, d'une langue heureusement plus simple que ses éloges impériaux - les allusions à Homère sont superficielles et se limitent à quelques emprunts de mots (p. 247-257).

10 Pourtant, ajouterai-je pour ma part, Eustathe est sans doute un des meilleurs connaisseurs d'Homère, de son temps et peut-être de tous les temps. Mais il ne pouvait hasarder que quelques clins d'œil à l'intention d'une poignée d'érudits de son acabit. En effet, un siècle auparavant, Psellos, autre considérable savant, dans sa Chronographie (VI, 61), faisait toucher du doigt l'abîme qui séparait les auditoires impériaux et les savants comme lui, en révélant l'impossibilité pour de tels auditoires de saisir une allusion à l'Iliade.

11 Mais en fin de compte, tout en œuvrant dans des conditions beaucoup plus difficiles que dans l'Antiquité, jusqu'au temps de Justinien compris, les savants byzantins ont permis aux modernes de relancer la réception d'Homère.

\section{AUTEURS}

\section{ALAIN BALLABRIGA}

cnrs

a.ballabriga@gmail.com 